\title{
Corrigendum: The Busier the Better: Greater Busyness Is Associated with Better Cognition
}

\author{
Sara B. Festini ${ }^{1 *}$, Ian M. McDonough ${ }^{1,2}$ and Denise C. Park ${ }^{1 *}$ \\ ${ }^{1}$ Center for Vital Longevity, School of Behavioral and Brain Sciences, University of Texas at Dallas, Dallas, TX, USA, \\ ${ }^{2}$ Department of Psychology, The University of Alabama, Tuscaloosa, AL, USA
}

Keywords: cognitive aging, busyness, cognitive engagement, episodic memory, middle age, old age

\section{A corrigendum on}

The Busier the Better: Greater Busyness Is Associated with Better Cognition by Festini, S. B., McDonough, I. M., and Park, D. C. (2016). Front. Aging Neurosci. 8:98. doi: 10.3389/fnagi.2016.00098

Reason for Corrigendum: In the originally published article, the scatterplots for Reasoning were incorrect in Figures 1, 2, although the reported statistics were accurate. The corrected Reasoning scatterplots appear in Figures 1, 2 below. This error does not change the scientific conclusions of the article in any way. The authors regret the mistake.

\section{OPEN ACCESS}

Edited and reviewed by: Shin Murakami,

Touro University-California, USA

*Correspondence: Sara B. Festini sara.festini@utdallas.edu; Denise C. Park

denise@utdallas.edu

Received: 23 May 2016 Accepted: 08 June 2016 Published: 20 June 2016

Citation:

Festini SB, McDonough IM and Park DC (2016) Corrigendum: The Busier the Better: Greater Busyness is Associated with Better Cognition

Front. Aging Neurosci. 8:148 doi: 10.3389/fnagi.2016.00148

\section{AUTHOR CONTRIBUTIONS}

SBF designed the study, analyzed the data, interpreted the results, and wrote the manuscript. IMMcD offered suggestions for analyses, helped interpret the results, and also critically edited the manuscript. DCP designed the study, helped interpret the results, and critically edited the manuscript. All authors approve the final version of the manuscript and agree to be accountable for the content of the work.

\section{FUNDING}

This study was supported by NIH Grant 5R37AG-006265-29 awarded to DCP. SBF is supported by the Aging Mind Foundation.

Conflict of Interest Statement: The authors declare that the research was conducted in the absence of any commercial or financial relationships that could be construed as a potential conflict of interest.

Copyright $\odot 2016$ Festini, McDonough and Park. This is an open-access article distributed under the terms of the Creative Commons Attribution License (CC BY). The use, distribution or reproduction in other forums is permitted, provided the original author(s) or licensor are credited and that the original publication in this journal is cited, in accordance with accepted academic practice. No use, distribution or reproduction is permitted which does not comply with these terms. 


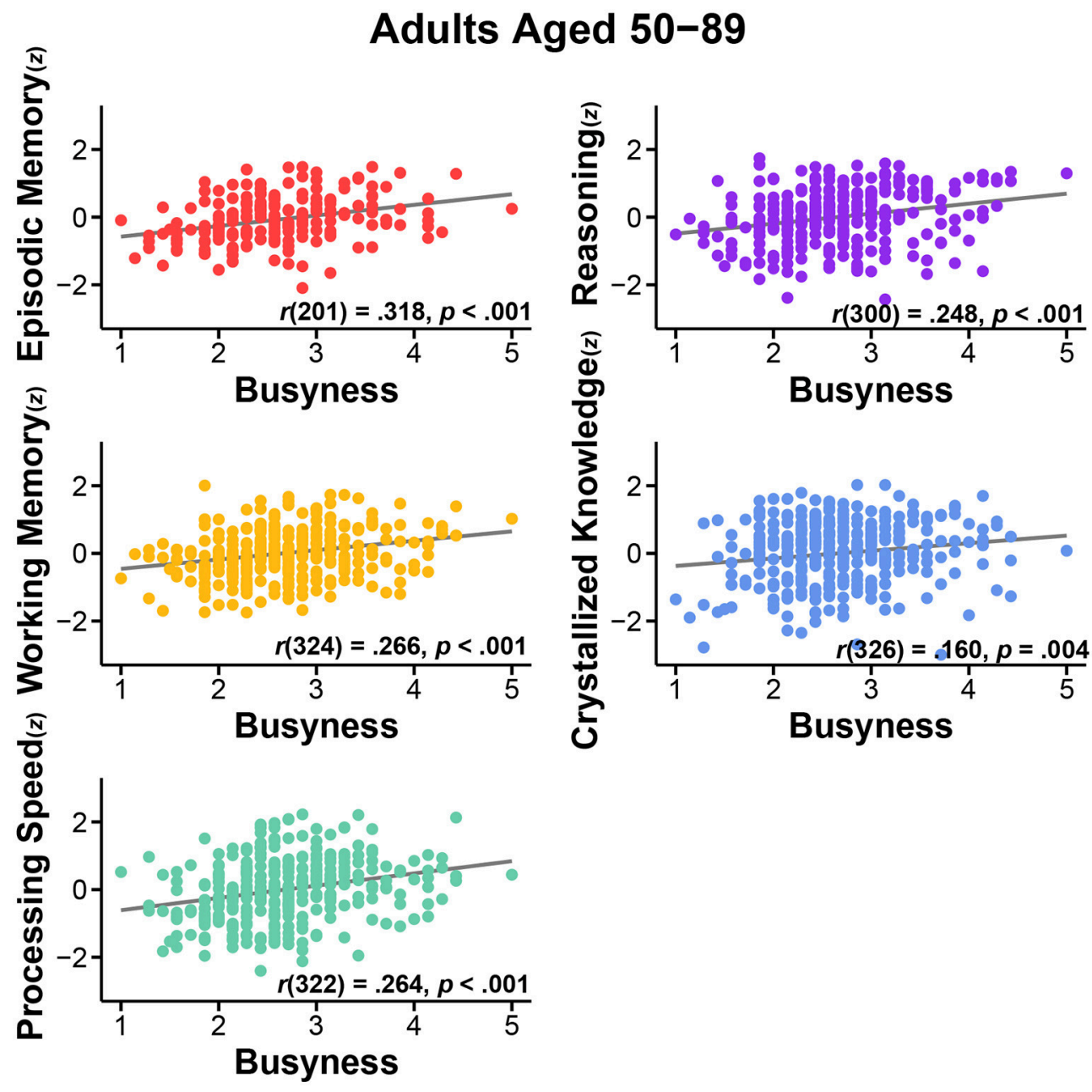

FIGURE 1 | Relationship between busyness and episodic memory, working memory, processing speed, reasoning, and crystallized knowledge in adults aged $50-89$. 


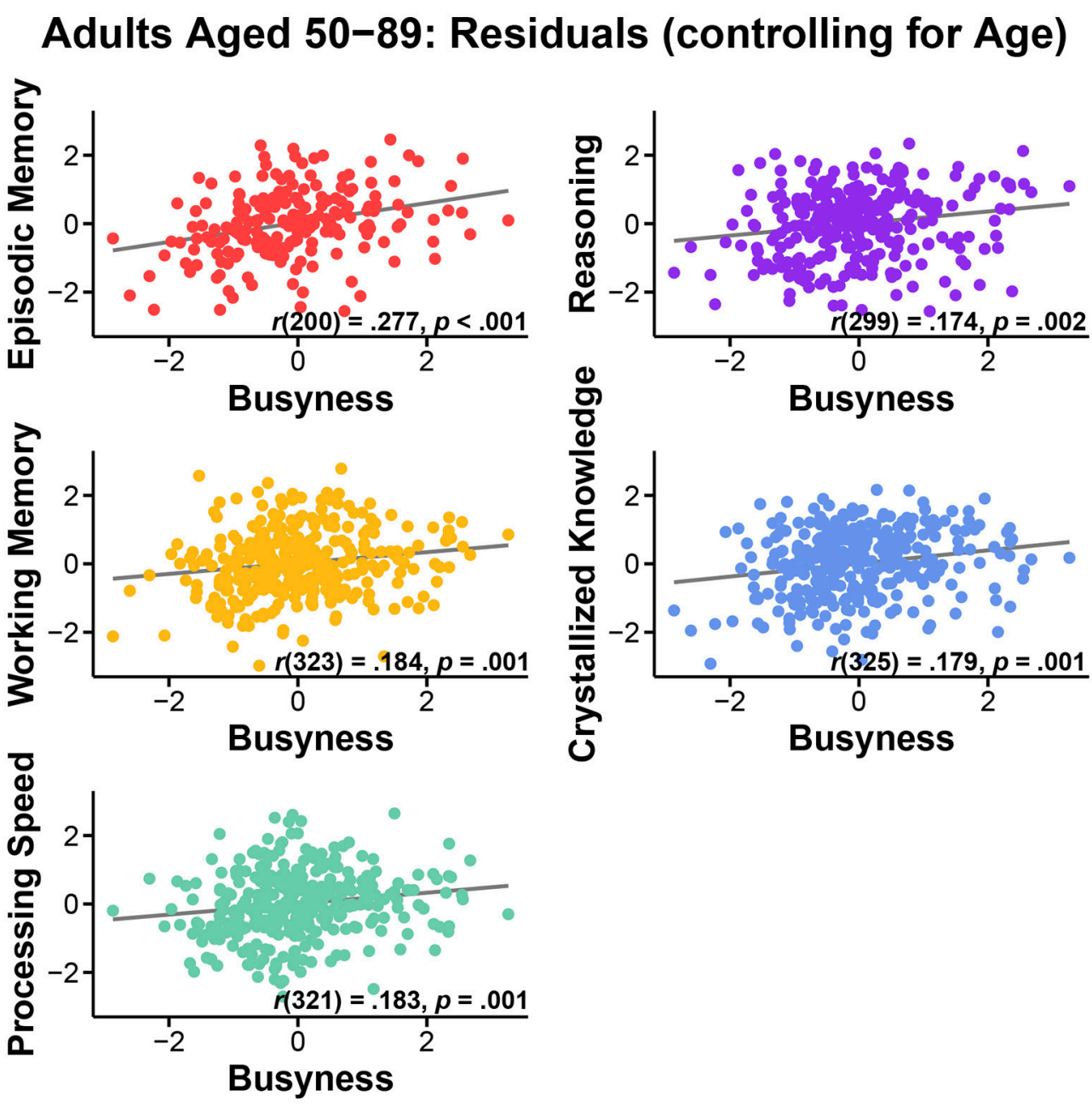

FIGURE 2 | Relationship between busyness and episodic memory, working memory, processing speed, reasoning, and crystallized knowledge in adults aged 50-89, after controlling for age. 